УДК 346.34

\title{
Ю.Е. Будникова
}

\section{ПРАВОВАЯ ПРИРОДА ДОГОВОРОВ В СФЕРЕ ПРЕДПРИНИМАТЕЛЬСКОГО РЫБОЛОВСТВА}

В статье анализируется правовая природа договорных отношений, возникающих при осуществлении предпринимательского рыболовства (промышленного и прибрежного). Рассматривается вопрос, к какому типу договоров можно отнести обязательства в сфере рыболовства - к гражданско-правовым, предпринимательским или природоресурсным, а также нормами какой отрасли законодательства должны регулироваться договорные отношения в сфере рыболовства.

Договоры, которые порождают предпринимательские обязательства в сфере рыболовства, а также предоставляют право на добычу (вылов) водных биоресурсов, одновременно являются основанием возникновения права на ведение предпринимательской деятельности и основанием перехода права собственности на природный ресурс. Обосновывается вывод о том, что указанные договорные отношения представляют собой предпринимательские в сфере природопользования, обладают публично-правовым характером и подлежат комплексному регулированию не только нормами природоресурсного, но и предпринимательского законодательства, но никак не гражданского. Для этого предлагается разработать новый правовой механизм регулирования предпринимательских обязательственных отношений в сфере рыболовства.

Ключевые слова: рыболовство, водные биоресурсы, промышленное рыболовство, предпринимательское рыболовство, договоры в сфере рыболовства, договор пользования водными биоресурсами.

DOI: $10.35634 / 2412-9593-2020-30-1-120-124$

Рыбное хозяйство в России всегда являлось важнейшей отраслью пищевой промышленности, которое включает в себя различные сегменты: от научно-исследовательской деятельности, прогнозирования запасов водных биоресурсов до организации торговли рыбной продукцией в стране и за рубежом. В статье мы рассмотрим лишь сферу рыболовства, представляющую собой предпринимательскую деятельность и ее договорные основы.

Из общего перечня видов рыболовства, установленных ст. 16 Федерального закона о рыболовстве $^{1}$ (далее - Закон о рыболовстве) к предпринимательству относится только промышленное и прибрежное рыболовство. Важно отметить, что законодатель определяет прибрежное рыболовство так же, как и промышленное рыболовство, только осуществляемое в привязке к какому-либо прибрежному субъекту Российской Федерации и юридическими лицами или индивидуальными предпринимателями, зарегистрированными в данном субъекте.

Значимым фактором ведения промышленного рыболовства является то, что оно осуществляется с учетом общего допустимого улова водных биологических ресурсов (ОДУ). Как гласит Закон, общий допустимый улов водных биоресурсов - это научно обоснованная величина годовой добычи (вылова) водных биоресурсов конкретного вида в определенных районах, установленная с учетом особенностей данного вида. В зависимости от того, установлен ли для водных биоресурсов общий допустимый улов или нет, определяются основания возникновения права на добычу (вылов) водных биологических ресурсов. Согласно ст. 19 Закона о рыболовстве, такими правовым основаниями являются решения органов государственной власти или договор пользования рыболовным участком, а также договор пользования водными биоресурсами, в отношении видов водных биоресурсов для которых ОДУ не устанавливается; договоры о закреплении доли квоты добычи (вылова) водных биоресурсов, когда ОДУ устанавливается.

Обратившись к истории возникновения договорных отношений в сфере рыболовства, необходимо отметить, что, как и в природопользовании в целом, развитие договорно-правовых основ зарождалось в период экономических реформ 1990-х гг. с момента провозглашения и закрепления в Конституции РФ частной собственности на землю и другие природные ресурсы, когда природные объекты стали вовлекаться в хозяйственный оборот. А практика лицензионного (разрешительного) порядка пользова-

\footnotetext{
${ }^{1}$ Федеральный закон от 20 декабря 2004 г. № 166-Ф3 «О рыболовстве и сохранении водных биологических ресурсов» // Собрание законодательства РФ. 2004. № 52 (ч. І). Ст. 5270.
} 
ния природными ресурсами постепенно заменялась договорными способами регулирования. Поэтому Закон о рыболовстве в свое время стал основой интенсивного внедрения данных инструментов.

Как справедливо отмечает Д.О. Сиваков, договорные отношения в области использования и охраны водных биоресурсов имеют публичный вектор развития, потому что особенности договорных способов и механизмов регулирования изучаемых общественных отношений обусловлены необходимостью обеспечить сохранность водных биоресурсов, которые далеко не безграничны; соответствие добывающих мощностей рыболовного флота научно обоснованным представлениям об объемах водных биоресурсов; управляемость самой отрасли рыбного хозяйства ${ }^{2}$.

Между тем, в силу Закона о рыболовстве (ч. 2 ст. 5), договорные обязательства и иные отношения, связанные с оборотом водных биоресурсов, регулируются гражданским законодательством. Иначе говоря, Закон о рыболовстве определил у всех обязательственных отношений в сфере рыболовства частно-правовой характер. А на самом деле в сфере рыболовства существует всего несколько видов договоров: договор о закреплении долей квот добычи (вылова) водных биоресурсов (ст. 33.1), договор пользования рыболовным участком (ст. 33.3), договор пользования водными биоресурсами (ст. 33.4), договор о закреплении и предоставлении доли квоты добычи (вылова) водных биоресурсов на инвестиционные цели (ст. 33.7). С 12.05.2019 г. появился новый договор - о закреплении и предоставлении доли квоты добычи (вылова) крабов в инвестиционных целях (ст. 33.8). Все они регулируются законом о рыболовстве, то есть природоресурсным законодательством и носят исключительно публичный характер. При этом в Гражданском кодексе РФ отсутствуют нормы, устанавливающие положения об обязательствах в сфере промышленного рыболовства.

Аналогично ситуация обстоит и со оборотом водных биоресурсов. В Законе о рыболовстве существует отсылочная норма (п.3 ст.10), которая устанавливает, что юридические лица и граждане, которые осуществляют рыболовство в порядке, предусмотренном указанным законом, приобретают право собственности на добытые (выловленные) водные биоресурсы в соответствии с гражданским законодательством. Однако ГК РФ предусмотрел основания приобретения права собственности на водные биологические ресурсы, как и на другие природные ресурсы, только в отношении свободного сбора ягод, свободной добычи (вылова) рыбы и других водных биологических ресурсов, сбора или добычи других общедоступных вещей и животных, то есть в порядке общего природопользования. В части водных биоресурсов общее пользование предусмотрено только для любительского и спортивного рыболовства.

Таким образом, в п. 3 ст. 10 Закона о рыболовстве речь идет только о приобретении права собственности на добытые (выловленные) водные биоресурсы в результате любительского или спортивного рыболовства, которое осуществляется преимущественно на водных объектах общего пользования свободно и бесплатно, а также рыболовства в целях обеспечения ведения традиционного образа жизни и осуществления традиционной хозяйственной деятельности коренных малочисленных народов Севера, Сибири и Дальнего Востока РФ.

Что же касается предпринимательской деятельности в сфере рыболовства, (промышленного и прибрежного рыболовства), то переход права собственности на добытые (выловленные) водные биоресурсы из государственной в собственность предпринимателя осуществляется на основании договоров пользования водными биоресурсами (ст. 33.4) и договоров о закреплении доли квоты добычи (вылова) водных биоресурсов (ст. 33.1, 33.7, 33.8). Названные договоры, прежде всего, предоставляют право на осуществление указанных видов деятельности, согласно заранее определенным условиям, и характеризуются необходимостью предварительного принятия решения о предоставлении данного права уполномоченным на то органом, а также возложением соответствующих обязанностей на предпринимателей. А по сути вместе с данным правом к предпринимателю переходит и право собственности на выловленные (добытые) водные биоресурсы.

Несомненно, договоры в сфере промышленного, в том числе, прибрежного рыболовства имеют сложную правовую природу, с одной стороны, порождают обязательства, а с другой - являются основанием перехода права собственности на природный ресурс. С одной стороны, если верить законодателю, они представляют собой основания возникновения частно-правовых отношений, цивилистических, а с другой - отношения, возникающие между государством и предпринимателем, носят исключительно публично-правовой характер.

\footnotetext{
${ }^{2}$ Сиваков Д.О. Особенности договорных отношений в области рыбного хозяйства // Журнал российского права. 2011. № 2. С. 56 .
} 
Так к каким же видам договоров можно отнести вышеуказанные обязательства в сфере рыболовства: к природоресурсным, гражданско-правовым или предпринимательским? Ответ на данный вопрос важен для определения норм права, которыми должны регулироваться договорные отношения в сфере рыболовства.

Необходимо признать, что научные дискуссии в этом направлении велись неоднократно. Представители цивилистической науки, разумеется, отстаивают точку зрения об отнесении указанных договоров к гражданско-правовым ${ }^{3}$, а ученые экологи-правоведы отмечают природоохранную сущность данных договоров ${ }^{4}$. Учитывая, что приведенная система обязательств связана с государственным регулированием рыбного хозяйства и представляет собой основания для осуществления предпринимательского рыболовства, справедливо будет признать их еще и предпринимательскими. Такой же позиции придерживаются и другие исследователи 5 .

Попробуем определить правовую категорию договорных отношений в сфере предпринимательского рыболовства. Разумеется, прежде всего это обязательственные отношения в области природопользования. Поскольку, как совершенно верно отмечает М.М. Бринчук, договор в сфере взаимодействия общества и природы является средством правового регулирования природопользования и охраны окружающей среды, как наряду с лицензией, так и самостоятельно, устанавливая соответствующие правоотношения ${ }^{6}$, то есть на основании указанных договоров возникает право на использование тех или иных природных объектов. И поскольку водные биологические ресурсы, как и любые другие природные ресурсы, представляют собой общественное достояние или общее благо и находятся в публичной, преимущественно в федеральной, собственности, то разумеется, договоры в области предпринимательского рыболовства являются публично-правовыми. Но такие договоры являются публично-правовыми еще и потому, что важнейшим признаком предпринимательского договора служит его тесная связь с государственным регулированием бизнеса ${ }^{7}$, и воля предпринимателя ограничена различными условиями и предписаниями со стороны государства, особенно когда такие договоры заключаются между государственными (муниципальными) органами и коммерческими организациями (индивидуальными предпринимателями).

Договоры в сфере рыболовства, которые, во-первых, наделяют предпринимателя правом пользования водными биоресурсами, а во-вторых, на их основании возникает право осуществления предпринимательской деятельностью, и при этом они являются инструментом регулирования природоресурсных отношений, такие договоры вполне признаются предпринимательскими в сфере природопользования, регулирующими и предпринимательские, и природоресурсные права и обязанности.

В связи с чем, как справедливо утверждает М.М. Бринчук ${ }^{8}$ природа, ставшая предметом куплипродажи, тенденциозно и часто необоснованно подпадает под действие норм гражданского права. А с какой стати публичные отношения по поводу объекта публичной собственности, оформленные публичным договором, регулируются частным правом?

Тогда как договорная конструкция, о которой идет речь в ГК РФ (ст. 420), регламентирует исключительно гражданские права и обязанности. А предпринимательские отношения в сфере рыболовства не являются гражданскими. Это становится очевидным, если подробнее рассмотреть договоры в области предпринимательского рыболовства.

\footnotetext{
${ }^{3}$ Договоры в предпринимательской деятельности / Беляева О.А., Витрянский В.В., Гасников К.Д. и др.; отв. ред. Е.А. Павлодский, Т.Л. Левшина М.: Статут, 2008. С. 265; Козяр Н.В., Митякина Н.М., Федорященко А.С. Гражданско-правовая сущность договоров о добыче водных биологических ресурсов // Бизнес в законе. Экономико-юридический журнал. 2016. № 5. С. 157-160.

${ }^{4}$ Сиваков Д.О. Указ. соч. С. 55-62; Бринчук М.М. Скоро гражданское право поглотит земельное... // Вопросы правоведения. 2010. № 4 (8). С. 111-128; Бринчук М.М. Соотношение экологического права с другими отраслями права // Государство и право. 2009. № 7. С. 25-37; Будникова Ю.Е. Выкуп земельных участков под приватизированными предприятиями. М.: Городец, 2009. С. 53-62.

5 Занковский С.С. Предпринимательские обязательства / отв. ред. В.В. Лаптев. М.: Волтерс Клувер, 2009. С. 304; Илюшина М.Н. Понятие, признаки и место предпринимательских договоров в системе гражданско-правовых договоров // Законы России: опыт, анализ, практика. 2009. № 1. С. 4-10; Андреев В.К. О сочетании частных и публичных начал в правовом регулировании предпринимательской деятельности // Журнал российского права. 2013. №1. C. 21-25.

${ }^{6}$ См.: Бринчук М.М. Экологическое право: учебник для студентов высших учебных заведений. М.: Изд. дом «Городец», 2009. С. 194.

${ }^{7}$ См.: Занковский С. С. Предпринимательские обязательства. М.: ООО «НБ-Медиа», 2012. С. 5.

${ }^{8}$ Бринчук М.М. Скоро гражданское право поглотит земельное... // Вопросы правоведения. 2010. № 4 (8). С. 118.
} 
Прежде всего, для совершения промышленного рыболовства во внутренних водах РФ, кроме морских (в пресноводных объектах) и прибрежного рыболовства во внутренних морских водах, сначала формируется рыболовный участок и подписывается договор пользования рыболовным участком. В таких случаях первым заключается договор пользования рыболовным участком, по результатам аукциона, а уже затем другие договоры заключаются и только при наличии первого. И эти договоры заключаются по результатам аукционов в следующих случаях: прекращения права пользования водными биоресурсами по основаниям, предусмотренным пп. 2-5 ч. 1 ст. 13; принудительного прекращения права на добычу (вылов) водных биоресурсов согласно ч. 2 ст. 13; в случае снятия ограничений рыболовства, в определенных районах и в отношении отдельных видов водных биоресурсов, для которых устанавливается ОДУ и определения соответствующей квоты добычи (вылова) водных биоресурсов при условии отсутствия действующих договоров о закреплении долей квоты добычи (вылова) водных биоресурсов.

Правовой неопределенностью характеризуется ч. 4 ст. 29 закона, согласно которой продажа права на заключение договора о закреплении долей квоты добычи (вылова) водных биоресурсов, в отношении которых ранее не осуществлялись промышленное рыболовство и (или) прибрежное рыболовство, или добыча (вылов) которых осуществляется в новых районах добычи (вылова) водных биоресурсов, или договора пользования указанными водными биоресурсами может осуществляться на аукционах по решению федерального органа исполнительной власти в области рыболовства. То есть вопрос о необходимости проведения аукциона остается на усмотрение Росрыболовства, хотя такие важные вопросы, которые могут повлечь за собой коррупционный характер решений, должны определяться исключительно федеральным законом.

Да и сама система торгов в России не является гарантом справедливых решений. Поскольку государственная контрактная система, с одной стороны, обеспечивает конкуренцию и открытость между хозяйствующими субъектами, а с другой - создает неравное положение тем, что эти субъекты, в финансовом смысле, имеют разные «весовые категории», а главным состязательным критерием оказывается цена. Так крупные рыболовецкие компании всегда будут в более выигрышном положении, нежели малый бизнес. Поскольку, как отмечают специалисты ${ }^{9}$, применение альтернативных процедур разрешено в строго регламентированных законом случаях, а также установлен запрет на заключение государственного контракта с единственным поставщиком, если процедура не состоялась.

Таким образом, проанализировав процедуру заключения договоров, предоставляющих право на добычу (вылов) водных биоресурсов, можно констатировать, что последние имеют только оболочку договорных обязательств, по сути же представляют собой публично правовой инструмент регулирования данных общественных отношений. Фактически такие договоры больше напоминают распорядительный акт, в котором отсутствуют свобода договора и равенство сторон - явные признаки гражданско-правовых (цивилистических) отношений.

По этой причине представляется ошибкой законодателя норма закона о рыболовстве, отсылающая к Гражданскому кодексу РФ в части регламентации оборота водных биоресурсов и обязательственных отношений. Такие отношения представляют собой предпринимательские в сфере использования природных ресурсов, обладают публично-правовым характером и подлежат комплексному регулированию не только нормами природоресурсного, но и предпринимательского законодательства, но никак не гражданскими нормами, на том основании, что «цивилистика всегда развивалась как правовое средство обслуживания быта и торговых сделок» ${ }^{10}$. А такая особенная область предпринимательства, как природопользование, требует исключительно публично-правового регулирования. Тем более что все договорные схемы, которые мы рассмотрели выше, регулируются законом о рыболовстве, а в ГК РФ отсутствуют какие-либо обязательства в сфере промышленного рыболовства.

Но справедливости ради следует отметить, что единственным договором в сфере рыболовства, порождающим гражданские (частные) права и обязанности, является договор, на основании которого осуществляется переход права на добычу (вылов) водных биологических ресурсов от одного лица к другому лицу (ст. 32 закона о рыболовстве), примерная форма которого утверждена распоряжением Правительства $Р \Phi^{11}$, так как он опосредует абсолютно горизонтальные отношения между участниками, основанные на равенстве сторон.

\footnotetext{
${ }^{9}$ См.: Предпринимательское право в XXI веке: истоки и перспективы. М.: Проспект, 2018. С. 306.

10 Занковский С. С. Возникновение и развитие доктрины хозяйственного права // Предпринимательское право в XXI веке: истоки и перспективы. М.: Проспект, 2018. С. 26.

${ }^{11}$ Распоряжение Правительства РФ от 21 июля 2008 г. № 1029-р «Об утверждении примерной формы договора, на основании которого осуществляется переход права на добычу (вылов) водных биоресурсов от одного лица к другому лицу» // Собрание законодательства РФ. 2008. № 30 (ч. ІІ). Ст. 3654.
} 
Важно отметить, что аналогичная ситуация происходит и в лесном, и в водном, и в земельном законодательстве, когда природоресурсные нормативные правовые акты отсылают регламентировать договорные отношения в сфере природопользования к гражданскому законодательству ${ }^{12}$.

Вместе с тем, как определяет ст. 129 ГК РФ, посвященная оборотоспособности объектов гражданских прав, земля и иные природные ресурсы могут отчуждаться или переходить от одного лица к другому в той мере, в какой их оборот допускается законодательством о земле и других природных ресурсах. Иными словами, ГК РФ сам установил приоритет специальных норм над гражданскими, если речь идет об обороте природных ресурсов, что и имеет место в нашем случае.

На основании изложенного можно утверждать, что действующая система договорных отношений по вылову (добыче) водных биологических ресурсов в целях предпринимательского рыболовства и правовое регулирование таковых не имеет системного, однородного и согласованного характера, что оказывает негативное влияние на развитие рыбного хозяйства страны и требует серьезных концептуальных и научно обоснованных преобразований. В связи с чем требуется разработать новый правовой механизм регулирования предпринимательских отношений в сфере рыболовства. В очередной раз убеждаемся, как необходимо принятие в России закона о государственном регулировании предпринимательства ${ }^{13}$, в котором важно уделить внимание положениям об обязательствах, поскольку создание предпринимательско-договорных инструментов поможет заполнить правовой вакуум также и в системе договорных механизмов регулирования рыболовства.

Поступила в редакцию 15.12.2019

Будникова Юлия Евгеньевна, кандидат юридических наук

Институт государства и права РАН

129164, Россия, г. Москва, Проспект Мира, д. 124

E-mail: yuliya_budnikova@mail.ru

\title{
Yu.E. Budnikova
}

\section{LEGAL NATURE OF CONTRACTS IN THE FIELD OF ENTREPRENEURIAL FISHING}

\author{
DOI: $10.35634 / 2412-9593-2020-30-1-120-124$
}

The article analyzes the legal nature of contractual relations arising from the implementation of entrepreneurial fishing (industrial and coastal). The question under examination is to which type of contracts we can attribute obligations in the field of fisheries: civil law, business or natural resources. Norms of which branch of legislation should govern contractual relations in the field of fisheries?

Contracts that generate entrepreneurial obligations in the field of fisheries, as well as provide the right to harvest (catch) aquatic biological resources, are at the same time the basis for the emergence of the right to conduct entrepreneurial activity and the basis for the transfer of a property right to natural resource. The article substantiates the conclusion that these contractual relations are entrepreneurial in the field of environmental management, have a public-law nature and are subject to complex regulation not only by the norms of natural resources law, but also entrepreneurial legislation, but not civil law. To this end, it is proposed to develop a new legal mechanism for regulating entrepreneurial obligations in the field of fisheries.

Keywords: fishery, aquatic biological resources, industrial fishery, business fishery, contracts in the field of fisheries, agreement on the use of aquatic biological resources.

Budnikova Yu.E., Candidate of Law

Institute of State and Law of RAS

Prospect Mira, 124, Moscow, Russia, 129164

E-mail: yuliya_budnikova@mail.ru

\footnotetext{
12 Подробнее об этом см.: Предпринимательское право в ХХІ веке: истоки и перспективы. М.: Проспект, 2018. С. 559.

${ }^{13}$ Автором неоднократно рассматривалась данная тема: Будникова Ю.Е. Проблемы механизма правового регулирования предпринимательства в сфере использования природных ресурсов // Приложение к журналу «Предпринимательское право». 2016. № 1. С. 40-46; Будникова Ю.Е. Некоторые аспекты государственного регулирования предпринимательской деятельности в сфере использования природных ресурсов // Нефть, газ и право. 2016. № 6 (132). С. 21-26.
} 